\title{
Article
}

\section{Factors related to implementation of nursing care ethical principles in Indonesia}

\author{
Ilkafah Ilkafah, ${ }^{1}$ Anestesia Pangestu Mei Tyas, ${ }^{1}$ Joni Haryanto \\ ${ }^{1}$ Nursing Program, Faculty of Vocational Studies, Universitas Airlangga, Surabaya; ${ }^{2}$ Faculty of Nursing, \\ Universitas Airlangga, Surabaya, Indonesia
}

\begin{abstract}
Background: The implementation of ethical principles is crucial in carrying out nursing care, since it is part of the 12 basic competencies, that should be possessed by a nurse. This study aims to analyse the factors associated with the implementation of nurses' ethical principles.

Design and Methods: This study used a quantitative research design, with a cross-sectional approach. The participants consisted of 389 nurses, working in the medical ward of the hospitals, in Indonesia. Data were analysed using the bivariate analysis, $t$-test, ANOVA and multiple linear regression test.

Results: There were no significant relationships between the demographic factors and the ethical behaviour. There was a relationship between caring behaviour and the application of ethical principles $(\mathrm{p}=0.000$, and a correlation coefficient of 0.602$)$.

Conclusion: Nurse ethical behaviour was improved, by increasing their caring attitude.
\end{abstract}

\section{Introduction}

The ethical aspect of nursing is very important for nurses in health services. Most of the issue of medical ethics, occurs in the implementation of nursing care, whether accidental or not. The complaints from patients, are about the indifference of nurses, to them, and their families. ${ }^{1}$ The number of ethical case violations that occurred in Indonesia, such as, the blistered baby abandoned by the nurse, the wrong injection, mishandling of patients, and the neglect in getting early treatment, proves that the services provided, does not meet the ethical principles.

In many studies, cases showed that, the services provided by nurses are not following the established ethic codes. Nurses are expected to be professionals, however, when this is not appropriately implemented, it results in the violation of the established ethic codes. Many medical errors occur in the scope of nursing practice, because of nurses' inabilities to meet the basic human needs. ${ }^{2}$ In the East Java region, ethical violations carried out by nurses often include, camera selfies in the operating room, sexual abuse, neglect of babies, etc. Also, based on student practice reports, it was observed that, there are many nurses that yell at patients, do not care, and often take nursing actions without informed consent. The results of the study showed that, nurses have difficulties in making decisions, and applying the ethical principles to nursing care. ${ }^{3}$

It is important to apply ethical principles to patients, without causing no harm. The ignorance to these ethical principles, cause physical and emotional injuries, such as feelings of dissatisfaction, disability, and even death, with patients' safety never to be realized. Furthermore, patients' dissatisfaction caused by these ignorant attitudes, ultimately tarnish the image of nurses and reduce the hospital's income, as patients become unhappy with the services provided, which in turn stops them from going back for treatment. Another case observed about nurses is that they are being portrayed by patients as being disrespectful, which leads to loss of trust, in the potentials of their medical skills. Nurses that observe ethical principles, and apply them in nursing care provides, adequate satisfaction, and maintain good relationships between the patients and other health workers, in a bid to build clients' confidence in the health services. Therefore, patients feel safer with the level of quality health services provided. ${ }^{4}$

There are seven nursing ethical principles namely, autonomy, non-maleficence, beneficence, justice, veracity, fidelity, and confidentiality. ${ }^{5}$ Nursing and health ethics, have become much of an interest issue to discuss. Every day, nurses are dealing with the ethical issues, as applying them is still needed to be studied further. ${ }^{6}$ The implementation of nursing care, should always make provisions for good care, uphold the code of ethics, apply ethical principles of medicating, and other related services. The nursing code of ethics is part of the guidelines for nurses, to prevent the misconceptions that occur, between the health workers and patients. This followed the results of a research that observed, a significant relationship between nurses' knowledge of ethic codes, job satisfaction, and complaint of ethical performance. ${ }^{7}$ The application of nursing ethics depends on the personal nurses, and other influential factors, which includes their caring behaviours. Furthermore, caring behaviours are for patients that, needs to be watched over by nurses. Nurse ethics, caring behaviours, and influential factors have not been studied yet, making it necessary to conduct factor analysis research related to the application of nurses' ethical behaviour, in implementing nursing care to patients.

\section{Significance for public health}

The implementation of nursing services should always make provisions for good care, uphold the code of ethics, apply ethical principles, and other related services. There are seven ethical principles of nursing, namely autonomy, non-maleficence, beneficence, justice, veracity, fidelity, and confidentiality. The implementation of nursing ethics depends on, the personal nurse, and other factors that serve as an influence. This study discusses the factors related to implementation of nursing care ethical principles in Indonesia. 


\section{Design and Methods}

Analytic survey with a cross-sectional study was conducted, to identify factors related to the application of ethical principles by nurses, in providing nursing care to patients and the influential factors. Participants included in this study, were nurses with minimal work length of one year. The selected participants were recruited, by using simple random sampling. Therefore, a total of 39 samples were included in this study, from four hospitals in Indonesia. The research ethic approval was obtained from the Institutional Review Board of Faculty of Nursing, Universitas Airlangga. Participants were briefed about the study, aims, and procedures, before signing the informed consent.

The questionnaire used was on caring behaviour, and the application of ethical principles by nurses. The caring questionnaire used, was adopted from Watson's 10 carative factors, ${ }^{8}$ while those used to determine application of ethical principles by nurses, was from the New Zealand Nurse Association, and developed by researchers. The questionnaire used to determine the application of ethical principles consisted of 31 favourable and 5 unfavourable questions. Data were analysed using ANOVA and $t$-test method, while using Pearson and multiple linear regression to determine the relationship between caring and ethical behaviour.

\section{Results and Discussions}

The result of the study showed that, $83 \%$ of the respondents were female, $59.1 \%$ were professional nurses, $66.8 \%$ were married, $85.6 \%$ of them held the position of associate therapists, and $56 \%$ were on the career path of being the first clinical nurse (Table 1). Furthermore, Table 2 showed that, there is no relationship between age and work length of respondents, with the application of ethical principles. The mean age of the respondents was 31.37 years, with the youngest being 22 years old, while the oldest was 59 years old. The young and old age of the respondents does not influence them in applying ethical principles to patients. The result further showed that $83 \%$ of the nurses were female, which when observed, showed that the average value of the application of ethical principles between men and women is only 0.2 and higher for women.

Between diploma nurses and professional nurses, there was an average difference of 0.28 , which was higher for those that are diplomatic. This interpreted that, the average score of implementing ethical principles, is the same for diploma and professional nurses. Furthermore, between professional and magister nurses, there is a difference in score of 5.24. This showed that, even though the difference is not significant, there is still a slight divergence in the average value of ethical principles implementation, among professional and magister nurses.

Furthermore, Table 3 showed that the mean value of nurses' caring behaviour is 163.07 , while the standard deviation sum is 20.069 . Therefore, the result of interval estimation concluded that, $95 \%$ believed that the average implementation of nurse caring behaviour is between 161.07, and 165.07. The highest mean value in the sub variable development of helping-trusting is 17.21. Professional nursing services should be able to make provision for individuals, families, and communities, with medical knowledge that help integrates, intellectual, technical, interpersonal, ethical, and legal competencies. Also, cognitive abilities enable intellects, to prioritize critical thinking in every form of decision making. Technical competence is also related to the multiple skills in performing nursing actions, following the standard operational procedure. Furthermore, ethical and legal competencies are shown when, nurses act morally, independently, and are fully responsible for carrying out nursing care professionally.

Nursing performance is a guideline and standard, in medicating services. Nursing performance is a standard practice, listed and stated in article 24, section 2, of Law No. 36 of 2009, also consisting both competency and fostering. ${ }^{9}$ The results further showed that, even though most of the perceptions as regards the application of ethic principles in implementing nursing care were good, the outcome of observations and interviews with several patients explained that, there were still complains about some nurses' incompetence. According to the results of this research, applying ethic codes and behaviours requires a leader with exemplifying abilities, in carrying out nursing care to patients. ${ }^{10}$ Most nurses feel that the ethical dilemma they experience, is often related to the act of nursing. The ethical dilemma that nurses experience without solutions makes them fatigued, helpless, and lose interest in work. $^{11}$

\section{Ethical behaviour in nurses according to demographic factors}

Based on the results, there was no significant relationship between the demographic characteristics and performance of nurses, in applying ethical principles to nursing care. The results of the bivariate analysis showed that, there was no difference between the gender, length of work, and age, with the ethical principles behaviour. There had been very few researches stating that, there is no relationship between gender and nurse performance. ${ }^{12}$ During short interviews with several nurses, most of them often discussed the problems they have with the patients. The research was conducted with quality care, as nurses applied ethical behaviour, which is a standard practice in the hospital. The implementation of ethic codes and principles, should always be carried out by health workers in hospitals, based on the regulation of the Minister of Health, 2018..$^{13}$

In Indonesia, there are clinical nurses having no significant relationship with ethical principles behaviour. From the statistical results, no difference was recorded, as the highest that do not have

Table 1. The characteristics of participants $(n=389)$.

\begin{tabular}{|c|c|c|c|c|c|c|}
\hline \multicolumn{3}{|l|}{ Characteristics } & \multicolumn{3}{|c|}{ Frequency } & $\%$ \\
\hline \multicolumn{7}{|l|}{ Gender } \\
\hline \multirow{2}{*}{\multicolumn{3}{|c|}{$\begin{array}{l}\text { Male } \\
\text { Female }\end{array}$}} & \multicolumn{3}{|c|}{66} & 17 \\
\hline & & & \multicolumn{3}{|c|}{323} & 83 \\
\hline \multicolumn{7}{|l|}{ Education } \\
\hline D3 & & & \multicolumn{3}{|c|}{156} & 40.1 \\
\hline S1/Ners & & & \multicolumn{3}{|c|}{231} & 59.4 \\
\hline S2 & & & \multicolumn{3}{|c|}{2} & 0.5 \\
\hline \multicolumn{7}{|l|}{ Marital status } \\
\hline Married & & & \multirow{2}{*}{\multicolumn{3}{|c|}{$\begin{array}{l}260 \\
129\end{array}$}} & 66.8 \\
\hline Single & & & & & & 33.2 \\
\hline \multicolumn{7}{|l|}{ Role in the wards } \\
\hline Primary nurse & & & \multirow{2}{*}{\multicolumn{3}{|c|}{$\begin{array}{c}56 \\
333\end{array}$}} & 14.4 \\
\hline Associate nurse & & & & & & 85.6 \\
\hline \multicolumn{7}{|c|}{ Career path in Indonesia nurses } \\
\hline Clinical Nurse & & & \multicolumn{3}{|c|}{24} & 6.2 \\
\hline Clinical Nurse I & & & \multicolumn{3}{|c|}{218} & 56.0 \\
\hline Clinical Nurse I & & & \multicolumn{3}{|c|}{123} & 31.6 \\
\hline Clinical Nurse I & & & \multicolumn{3}{|c|}{23} & 5.9 \\
\hline Clinical Nurse I & & & \multicolumn{3}{|c|}{1} & 0.3 \\
\hline Clinical Nurse & & & \multicolumn{3}{|c|}{0} & 0 \\
\hline Characteristic & Mean & Median & Modus & Min-Max & SD & CI $95 \%$ \\
\hline Age & 31.37 & 30.0 & 30 & $22-59$ & 5.86 & $30.78-31.95$ \\
\hline Length of work (year) & 7.07 & 6.0 & 2 & $1-32$ & 5.53 & $6.52-7.62$ \\
\hline
\end{tabular}


a functional position (pre-clinical nurses), was recorded for the average score, even though it was not significant. The nurses are doing their best to be able to attain the height of a functional position (first clinic nurse), in the hospital. Another study reported that, nurses' demographic variables, did not have a significant effect on their ethical reasoning ability. ${ }^{12}$ There are many factors related to ethical principles behaviour in nurses, such as, individual character, responsibility, communication challenges, organizational preconditions, support systems, educational, and cultural development. Awareness of professional ethics, help nurses and healthcare professionals in providing better services for patients. ${ }^{14}$ Furthermore, leadership plays a significant role in developing, and maintaining nursing ethics. Ethical nurse leaders create work environments that, impact employee choices, behaviours, and values. ${ }^{15,16}$ Nurse manager have to support staff, in conducting ethically sound care for ethical reflection. ${ }^{17}$

\section{Relationship between caring attitude and application of ethical principles}

The results of this study showed that, even though the application of ethics has no relationship at all with the characteristics of the respondent, the administration of ethics related to that of nurse caring behaviour is observed. Nurses that have a good caring attitude, automatically carry out ethical principles, in providing nursing care to patients. When observed from the relationship between sub variables, those most related are, the development of a helping-trusting, instillation of faith with hope, and assistance of human needs. Caring is a central or core concept for nursing, yet not considered as a unique paradigm for medical profession, because other health specializations consider it as an integral part of their abilities, which consist of knowledge and skill. Watson defined caring as a science, with its perspective based on relationship ontology, in which all those involved, have an agreement with one another. Caring behaviour, according to Watson, is a process carried out by nurses, and is discussed as part of the ten factors used in nursing practice, in several different clinical settings. ${ }^{18}$

The impact of caring behaviour felt by nurses, is expected to be a source of motivation for them to work, optimize performance, and apply the ethical principles in nursing care. Not many research results have been conducted and published, regarding the relationship between caring behaviour, and the ethical application of nurses. Nurses that have a sense of respect for human existence see clients as unique individuals, and assume that they are entitled to treatment, by their dignity as humans. Nurses provide care by

Table 2. Ethical behaviour according to demographic factors.

\begin{tabular}{|c|c|c|c|c|c|}
\hline Variable & Mean & SD & SE & p-value & N \\
\hline $\begin{array}{l}\text { Gender: } \\
\text { Male } \\
\text { Female }\end{array}$ & 123.70123 .90 & 10.68910 .867 & 1.3160 .605 & $0.773^{*}$ & $\begin{array}{c}66 \\
323\end{array}$ \\
\hline $\begin{array}{l}\text { Education } \\
\text { Diploma in nursing } \\
\text { BSN-PN programs } \\
\text { Magister nursing }\end{array}$ & $\begin{array}{c}124.02123 .74 \\
128.50\end{array}$ & $\begin{array}{c}11.24810 .608 \\
3.536\end{array}$ & $\begin{array}{c}0.9010 .699 \\
2.500\end{array}$ & $0.920^{* *}$ & $\begin{array}{c}156231 \\
2\end{array}$ \\
\hline $\begin{array}{l}\text { Marital status } \\
\quad \text { Married } \\
\text { Single }\end{array}$ & 123.70124 .22 & 10.91110 .678 & 0.6770 .940 & $0.433^{*}$ & 260129 \\
\hline $\begin{array}{l}\text { Role in the wards } \\
\text { Primary nurse } \\
\text { Associate nurse }\end{array}$ & 123.32123 .96 & 10.55810 .875 & 1.4150 .596 & $0.673^{*}$ & $\begin{array}{c}56 \\
333\end{array}$ \\
\hline $\begin{array}{l}\text { Career path in Indonesia nurses } \\
\text { Clinical Nurse } \\
\text { Clinical Nurse I } \\
\text { Clinical Nurse II } \\
\text { Clinical Nurse III } \\
\text { Clinical Nurse IV } \\
\text { Clinical Nurse V }\end{array}$ & $\begin{array}{c}126.62123 .98123 .50 \\
122.17119 .00 \\
0\end{array}$ & $\begin{array}{c}9.230 \\
10.94911 .034 \\
10.299 \\
- \\
0\end{array}$ & $\begin{array}{c}1.8840 .7420 .995 \\
2.147 \\
- \\
0\end{array}$ & $0.648^{* *}$ & $\begin{array}{c}24 \\
218 \\
123 \\
23 \\
1 \\
0\end{array}$ \\
\hline
\end{tabular}

Table 3. Relationship between caring and ethical behaviour.

\begin{tabular}{|c|c|c|}
\hline Variable & Coefficient correlation & p-value \\
\hline Caring behaviour & 0.602 & $0.000^{*}$ \\
\hline Subvariable Humanistic-altruistic values & 0.285 & $0.317^{* *}$ \\
\hline Instillation of faith-hope & 0.900 & $0.001 * *$ \\
\hline Cultivation of sensitivity to oneself and others & -0.039 & $0.912^{* *}$ \\
\hline Development of a helping-trusting & 0.935 & $0.000 * *$ \\
\hline Promotion and acceptance of the expression of positive and negative feelings & 0.356 & $0.287^{* *}$ \\
\hline Systematic use of the scientific. problem solving method of decision-making & -0.272 & $0.322 * *$ \\
\hline Promotion of interpersonal teaching & 0.394 & $0.252^{* *}$ \\
\hline Provision for a supportive. protective environment & 0.777 & $0.720^{* *}$ \\
\hline Assistance with gratification of human needs & 0.957 & $0.002 * *$ \\
\hline Allowance for existential-phenomenological forces & -0.155 & $0.545^{* *}$ \\
\hline
\end{tabular}

Dependent variable: ethical behaviour; ${ }^{*}$ Pearson test; ${ }^{* *}$ multiple regression linear test. 
applying ethical principles, such as, respecting client choices, not differentiating between patients, allowing Ill people to participate in their care, and so much more. ${ }^{19}$ Caring relationship formed between the client and the nurse, helps the therapist to know the patient as a unique individual, while determining appropriate and effective nursing actions for the ill personality. ${ }^{20}$

Caring behaviour is an interaction between nurse and client, which is continuous in providing nursing care. ${ }^{21}$ The aspect considered by the patient as nurse caring behaviour is that, the therapist nurse should know what is being conducted, what is wanted, have the ability to answer questions clearly, and provide information needed, in a language that is easily understood. The act of caring also means, respecting the differences and uniqueness of the client, as an individual. ${ }^{22,23}$ Respecting patient spiritual beliefs, culture diversity, and social issues, are the key points to provide ethical nursing care. Furthermore, moral considerations and delivery of compassionate care to patients, are the reasons that motivate, and encourage sick people, to engage them in activities relating to caring behaviour. ${ }^{24,25}$ Ethical behaviour is conducted by nurses, when they possess knowledge about humans, aspects of growth and development, a response to a changing environment, limitations, strengths, and human needs. Nurses that know much about human feelings, observe clients as humanistic beings, that should be treated according to their rights.

\section{Conclusions}

Generally, the application of ethical principles by nurses has been terrific, there are only a few objectives that have not been carried out, due to their ignorance and lack of information, regarding what should be done to apply ethical principles in nursing care.

Correspondence: Ilkafah Ilkafah, Faculty of Vocational Studies, Universitas Airlangga, Lebak adi, Sugio District, Lamongan Regency, Indonesia.

Tel. +62.31 .5033869 - Fax: +62.31 .5053156$

E-mail: ilkafah@vokasi.unair.ac.id

Key words: Caring; ethical principles; nurses; nursing care.

Acknowledgment: The authors are grateful to the Faculty of Vocational Studies, Universitas Airlangga, Surabaya, Indonesia, for their kind support, and encouragements during this study.

Contributions: All authors contributed equally to this article.

Conflict of interests: The authors declared no potential conflict of interest.

Funding: This study was financially supported by Faculty of Vocational Studies, Universitas Airlangga, Surabaya, Indonesia

Ethics approval: This study has been approved by the Health Research Ethics Committee of Faculty of Nursing, Universitas Airlangga, Surabaya, Indonesia (No. 2063-KEPK).

Conference presentation: Part of this study was presented at the $1^{\text {st }}$ International Nursing and Health Sciences Symposium, November $13^{\text {th }}$ to $15^{\text {th }} 2020$, Brawijaya University, Malang, Indonesia.

Received for publication: 14 January 2021.

Accepted for publication: 18 March 2021.

CCopyright: the Author(s), 2021

Licensee PAGEPress, Italy

Journal of Public Health Research 2021;10:2211

doi:10.4081/jphr.2021.2211

This work is licensed under a Creative Commons Attribution

NonCommercial 4.0 License (CC BY-NC 4.0).

\section{References}

1. Haddad LM, Geiger RA. Nursing ethical considerations. Treasure Island: StatPearls Publishing; 2020.

2. Sorrell JM. Errors: Shaping a culture of safety in healthcare. Online J Issues Nurs 2017:22:2.

3. Schröder-Bäck P, Duncan P, Sherlaw W, et al. Teaching seven principles for public health ethics: Towards a curriculum for a short course on ethics in public health programmes. BMC Med Ethics 2014;15:1-10.

4. Tschudin V. Nursing ethics: The last decade. Nurs Ethics 2010;17:12731 .

5. Marquis BL, Huston CJ, Marquis BL, et al. Leadership roles and management functions in nursing: Theory and application. Philadelphia: Lippincott Williams \& Wilkins; 2012.

6. Peter E. Ethics in healthcare: Nurses respond. Online J Issues Nurs 2018;23.

7. Mohajjel-Aghdam A, Hassankhani $\mathrm{H}$, Zamanzadeh $\mathrm{V}$, et al. Knowledge and performance about nursing ethic codes from nurses' and patients' perspective in Tabriz teaching hospitals, Iran. J Caring Sci 2013;2:219-27.

8. Watson J. Assessing and measuring caring in nursing and health sciences. Springer; 2009.

9. Indonesian National Nurses Association. [Pedoman perilaku sebagai penjabaran kode etik keperawatan (Code of conduct as an elaboration of the nursing code of ethics)].[Book in Indonesian]. Jakarta: DPP PPNI; 2017.

10. Poikkeus T, Leino-Kilpi H, Katajisto J. Supporting ethical competence of nurses during recruitment and performance reviews - the role of the nurse leader. J Nurs Manag 2014;22:792-802.

11. Suhonen R, Stolt M, Habermann M, et al. Ethical elements in priority setting in nursing care: A scoping review. Int J Nurs Stud 2018:25-42.

12. Safavi F, Ebrahimi H, Namdar Areshtanab H, et al. Relationship between demographic characteristics and ethical reasoning of nurses working in medical wards. J Clin Diagnostic Res 2018;12:LC01-4.

13. Ministry of Health of the Republic of Indonesia. [Regulation of the Minister of Health of the Republic of Indonesia Number 42 of 2018 concerning the Ethics and Law Committee of Hospitals].[In Indonesian]. 2018.

14. Dehghani A, Mosalanejad L, Dehghan-Nayeri N. Factors affecting professional ethics in nursing practice in Iran: a qualitative study. BMC Med Ethics 2015;16:1-7.

15. Zhang N, Li M, Gong Z, et al. Effects of ethical leadership on nurses' service behaviors. Nurs Ethics 2019;26:1861-72.

16. Özden D, Arslan GG, Ertuğrul B, et al. The effect of nurses' ethical leadership and ethical climate perceptions on job satisfaction. Nurs Ethics 2019;26:1211-25.

17. Devik SA, Munkeby H, Finnanger M, et al. Nurse managers' perspectives on working with everyday ethics in long-term care. Nurs Ethics 2020;27:1669-80.

18. Watson J. Nursing science as contex: The philosophy and science of caring. Boulder: University Press of Colorado; 2008.

19. Milliken A. What it is and why it matters. Online J Issues Nurs 2018;23.

20. Black BP. Professional nursing concepts \& challenges. Elsevier; 2014.

21. Ozan YD, Okumus H, Lash AA. Implementation of Watson's theory of human caring: A case study. Int J Caring Sci 2015;8:25-35.

22. Berhe H, Berhe H, Bayray A, et al. Status of caring, respectful and compassionate health care practice in Tigrai Regional State: Patients' perspective. Int J Caring Sci 2017;10:1118-28.

23. Liu J, Mok E, Wong T. Caring in nursing: investigating the meaning of caring from the perspective of cancer patients in Beijing, China. J Clin Nurs 2006:188-96.

24. Linton M, Koonmen J. Self-care as an ethical obligation for nurses. Nurs Ethics 2020;27:1694-702.

25. Al-Breiki M. What influence nurses practice more: Law or ethics. JOJ Nurse Health Care 2017;5:3-5. 